\title{
Decir el malestar y malestar en el decir en los márgenes urbanos de Buenos Aires*
}

\author{
Saying Discomfort and Discomfort in Saying \\ at the Urban Margins of Buenos Aires
}

\author{
María E. Epele ${ }^{* *}$ \\ Consejo Nacional de Investigaciones Científicas y Técnicas (Conicet), Argentina
}

DOI:10.22380/2539472X.490

\begin{abstract}
RESUMEN
Basada en la etnografía realizada en contextos de desigualdad y pobreza (2013-2017) en el Área Metropolitana de Buenos Aires, este artículo problematiza las relaciones entre los malestares asociados a las condiciones materiales de vida y la práctica de psicoterapias en personas cuyos trabajos son precarios y flexibles. El objetivo es examinar los modos de enunciación de ciertos malestares en términos de ensambles frágiles e inestables, hechos de diferentes materiales, orígenes y cronologías en estos contextos sociales. Después de revisar las orientaciones y argumentos dominantes en la antropología del sufrimiento, se exploran estos malestares como lenguajes menores, por las características particulares que asumen en estas poblaciones.
\end{abstract}

Palabras clave: etnografía, psicoterapias, malestares, modos de enunciar.

\begin{abstract}
Based on an ethnography carried out in contexts of inequality and poverty (2013-2017) in the Metropolitan Buenos Aires Area, this article problematizes the relationship between discomforts associated with the material living conditions of life and the practice of psychotherapies among people with precarious and flexible jobs. The objective is to examine the ways of enunciating certain discomforts and discontents in terms of fragile and unstable assemblies, made of different materials, origins and chronologies in these social contexts. After reviewing the dominant orientations and arguments in the anthropology of suffering, these discomforts are explored as minor languages given the particular characteristics they assume in these populations.
\end{abstract}

Keywords: ethnography, psychotherapies, discomforts, ways of saying.

\footnotetext{
* Esta obra está bajo licencia internacional Creative Commons Reconocimiento-NoComercialSinObrasDerivadas 4.0

** Investigadora principal del Consejo Nacional de Investigaciones Científicas y Técnicas (Conicet) y profesora de la Facultad de Ciencias Sociales de la Universidad de Buenos Aires. Doctora en Ciencias Naturales, con orientación en Antropología de la Universidad Nacional de La Plata. maria.epele33@gmail.com / https://orcid.org/0000-0002-6742-2510
} 


\section{Introducción}

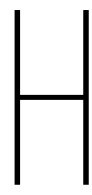

ace años que algo en los modos de decir y escribir acerca de los sufrimientos en los sectores sociales más desfavorecidos viene produciendo disonancias, haciendo ruido. No solo ciertas economías discursivas referidas al sufrimiento social han dominado nuestras sensibilidades sociales y académicas (Bourdieu 1999; Kleinman y Kleinman 1991), también las políticas y moralidades del sufrir han sido revisadas críticamente, entre otras cosas, por incluir lógicas que reproducen la desigualdad que denuncian (Fassin 2012).

Con la acumulación de etnografías en contextos de marginalidad, ciertos sufrimientos y catástrofes de salud se convirtieron en paradigmáticos de las poblaciones que viven en la desigualdad y la pobreza del capitalismo en el sur global (hambre y malnutrición, violencias y abusos, epidemias, consumos problemáticos, criminalización y represión, entre otros) (Biehl 2009; Briggs y Mantini 2003; Epele 2010; Tiscornia 2004). Las diversas perspectivas antropológicas sobre el sufrimiento elaboradas para analizar estos problemas tienen, sin embargo, un bajo poder explicativo respecto de un espectro de malestares que no llegan a ser categorizados, o ni siquiera a recibir un nombre o diagnóstico. Estos malestares se refieren a un conjunto de afecciones y aflicciones que erosionan y dan forma a lo cotidiano, desde décadas atrás y en estos contextos sociales (Epele, en prensa).

Basada en la etnografía realizada sobre psicoterapias en contextos de desigualdad y pobreza, este trabajo problematiza ciertos malestares que emergen entre quienes viven de trabajos precarios y flexibles en el sur del Área Metropolitana de Buenos Aires ${ }^{1}$ (AMBA). Debido a las profundas reformas y crisis cíclicas producidas por la expansión neoliberal, la asociación entre trabajo precario, pobreza y marginación constituye un nudo que revela la reducción extrema de la movilidad social y la territorialización de la marginación (Fernández 2016; Harvey 2006; Svampa 2005, 2016).

Con este horizonte, el objetivo de este trabajo es doble. Por un lado, por medio del análisis de un caso particular que incluye referencias específicas a otros, se examinan los modos de enunciación de ciertos malestares, en términos de ensambles frágiles e inestables, hechos de diferentes materiales, insumos, orígenes y cronologías. Como parte del repertorio de estudios etnográficos de la salud, focalizar el análisis en un caso hace visible y facilita la escritura en detalle de las

\footnotetext{
1 El Área Metropolitana de Buenos Aires es una delimitación utilizada por el Instituto Nacional de Estadística y Censos (Indec) que incluye a la ciudad de Buenos Aires y los veinticuatro partidos del Gran Buenos Aires que la bordean. [N. de la e.]
} 
experiencias, contextos y modos de enunciar los malestares que este trabajo tiene como objeto. Estos modos de enunciación se analizan como lenguajes menores (Deleuze y Guattari 1975, 2004), dentro de las políticas que distribuyen los modos de tomar la palabra sobre problemas ligados a las condiciones de vida y de trabajo en las zonas marginalizadas del espacio urbano (Rancière 1996; 2009). Por otro lado, tras revisar brevemente las orientaciones y perspectivas dominantes en la antropología sobre el sufrimiento y las psicoterapias, el objetivo es explorar otros modos de abordar y escribir los malestares que contemplen las características particulares asumidas en estas poblaciones. Por lo tanto, con el fin de problematizar estos malestares, se hace necesario modificar las relaciones entre los argumentos y lo sensible, para investigar zonas de experiencias no sometidas a los procesos dominantes de categorización y que contagian con su ambigüedad el lenguaje que los caracteriza (Biehl y Locke 2010).

Para comenzar, se examinan brevemente los modos en que ciertas antropologías sobre tratamientos psi (psicológicos, psiquiátricos, etc.) ${ }^{2}$ han sido atravesadas por desarrollos sobre el sufrimiento social que, desde fines de los ochenta, integran las investigaciones sobre la desigualdad y las lógicas de violencia y de poder (Bourdieu 1999; Das 2007; Kleinman, Das y Lock 1997; Lakoff 2005). A diferencia de estos desarrollos que privilegian la traducción de las consecuencias de la desigualdad y la pobreza en términos de sufrimiento y dolencias, y que se transforman en objetos de terapias psicológicas o psiquiátricas, este artículo explora malestares que no se disocian de las condiciones materiales de vida, injusticia y marginación. En lugar de reproducir o criticar los argumentos clásicos, se busca abrir al examen ciertas micrológicas de experiencias de malestar que coexisten y crecen en estos contextos, a contramano de los modos dominantes de padecer que se expresan en categorías diagnósticas o locales. Lejos de promover una lectura tautológica, el argumento central trabaja recursivamente con diferentes dimensiones: las experiencias, los sentidos, las expresiones, y los modos de entender y escribir. En segundo lugar, a través del análisis de un caso particular, combinado con la información de un repertorio de casos, se analizan las relaciones entre lo sensible, el trabajo precario, las condiciones materiales de vida y las psicoterapias.

La historia reciente de las poblaciones que viven en los barrios marginalizados del sur de la región metropolitana de Buenos Aires está atravesada por

2 Con las nociones de tratamientos y tecnologías psi se hace referencia al desarrollo de saberes, discursos, prácticas, técnicas e instituciones ligadas a la conformación del campo psi. Siguiendo a Foucault (2007), desde mediados del siglo XIX este campo se viene desarrollando conjuntamente con la constitución de diferentes disciplinas que asumen la función psi en los sujetos que abordan -psiquiatría, psicología, psicopedagogía, etc.- (Rose 1998). 
ciclos de crisis extremas, desmantelamientos y mejoramientos temporarios que modifican y precarizan los modos de subsistir y sobrevivir en los márgenes urbanos (Svampa 2005, 2016) ${ }^{3}$. Siguiendo la perspectiva de la destrucción creativa (Harvey 2004, 2006), las experiencias de malestar y los modos de enunciarlos se mimetizan con estos procesos, siempre colectivos, políticos y en peligro de demolición, destrucción y reconstrucción.

Finalmente, analizar estas experiencias de malestar y los modos de enunciarlas implica revisar las perspectivas de análisis en antropología que se diferencian por la importancia de la representación en los vínculos entre dolencias y lenguajes. Las acciones de decir y hablar sobre este tipo de malestares consisten en ensamblar diferentes materiales e insumos del ámbito terapéutico, la vida ordinaria, diferentes idiomas, saberes, ambientes, economías, políticas, genealogías y cronologías. Por último, sugiero que, sin problematizar estos malestares y las orientaciones para su estudio a la luz de los contextos y procesos locales, las etnografías del padecer pueden llevarnos a reproducir los argumentos ya dominantes, minimizando o desestimando cualquier experiencia que los confronte. Especialmente, cuando de los modos de dar respuesta al sufrimiento se trata.

\section{Etnografías, malestares y escrituras}

Las investigaciones antropológicas sobre el campo psi en contextos de desigualdad y pobreza han asumido diferentes orientaciones que privilegian o combinan las dimensiones culturalistas, económico-políticas y los estudios sociales de las ciencias (Biehl y Locke 2010; Dias 1986; Fassin 2012; Lakoff 2005). A su vez, los estudios varían de acuerdo con la problemática que indagan, es decir, se encuentran aquellos que focalizan el análisis de diagnósticos expertos psi (psicosis, trauma, etc.); en categorías nativas o locales (nervios, abusos, maltratos, etc.), y en un repertorio heterogéneo de problemas formulados en términos de las ciencias sociales (violencias, dolor, injusticia, opresión, etc.).

Con respecto al desempleo, el Área Metropolitana de Buenos Aires experimentó extremas variaciones en las últimas décadas. En 1974 fue del 4,4\%. Durante la dictadura militar, creció hasta el 19,1\%. Desde el retorno de la democracia en 1983 a la actualidad los índices de pobreza han fluctuado hasta llegar a picos de más del 45\% (durante la hiperinflación de 1989 y la gran crisis del 2001). Tomando como referencia el 2014, el aumento de la pobreza se aceleró desde el 2016 y llegó hasta el 33\% en la crisis actual con un incremento del desempleo y la segregación social (Salvia 2018). Según los últimos datos, el empleo formal es del 38,1\%; el trabajo precario, del 27\%; el trabajo inestable, del 24,3,\% y el desempleo, del 9,9\% (Salvia 2018). Sin embargo, los índices más altos de desempleo y trabajo precario se concentran en los barrios populares, villas y asentamientos (Águila y Lo Vuolo 2017). 
La mayoría de las antropologías sobre problemas psi, sin embargo, han sido atravesadas por las perspectivas sobre el sufrimiento y el dolor que irrumpieron y se desplegaron global y localmente desde fines de la década de los ochenta (Boltanski 1999; Bourdieu 1999; Kleinman, Das y Lock 1997). Estos desarrollos han modificado los lenguajes, regionalizado las perspectivas sobre el sufrir y desafiado los métodos de investigación. La progresiva relevancia del sufrimiento social en antropología y ciencias sociales se ha complementado con su creciente importancia en discursos, agendas y programas políticos del norte y el sur global durante las décadas de los ochenta y noventa (Fassin 2012). La emergencia del sufrimiento y el dolor como paradigmas de inteligibilidad se corresponde, a su vez, con un contexto histórico caracterizado por el despliegue del neoliberalismo, el aumento de conflictos regionales y guerras, los regímenes políticos que combinan la desigualdad y la criminalización, el crecimiento exponencial de migrantes y desplazados, en tanto modos globales y locales de gobierno de la pobreza y de acumulación por desposesión del capital. La agenda de estudios sobre el sufrimiento social en antropología ha sido modelada por este conjunto de experiencias de padecer producidas por estos procesos y conflictos (Kleinman, Das y Lock 1997). Desde diferentes aproximaciones, el hablar en general y sus relaciones con los discursos entre los subalternos, y las relaciones entre palabras y silencios en lo ordinario se han convertido en uno de los focos centrales de la agenda analítica del sur global (Das 2007; Spivak 1998).

Aun considerando estas variaciones, los diferentes argumentos que articulan sufrimiento social y problemas psi giran en torno a las críticas sobre los modos en que los problemas sociales son transformados en sufrimientos individuales por lenguajes expertos, que los hacen abordables por las terapéuticas psi (Bourgois y Schonberg 2009; Kleinman 1995, 2000; Scheper-Hughes 1992). Por un lado, eludiendo la patologización y la psicologización, estos desarrollos privilegian la traducción de la desigualdad y la pobreza con respecto a sufrimientos sociales y dolencias, que generalmente son expresados en terminologías locales y de los propios actores sociales. Por el otro, se ha cuestionado la relevancia de las nociones de sufrimiento social y diversos tipos de dolor, ya que desdibujan los fundamentos económicos y políticos de los problemas sociales al transformar la desigualdad en exclusión, la dominación en infortunio y la injusticia en trauma (Fassin 2012; Kleinman y Kleinman 1991).

De manera articulada y contemporánea con los desarrollos teóricos sobre sufrimiento social, las orientaciones sobre las emociones y los cuerpos fueron adquiriendo importancia en la antropología de la salud (Abu-Lughod y Lutz 1986; Jimeno 2004). Desde estas perspectivas, se han revisado los presupuestos 
dualistas de las emociones que se expresan en los modelos expertos (biomédicos, $p s i$, etc.). También se han examinado los modos en que los procesos económicos y políticos se corporizan y traducen en malestares y dolencias, las que son normatizadas, moralizadas e individualizadas por las tecnologías terapéuticas (Scheper-Hughes 1992).

Con décadas de etnografías sobre sufrimientos y dolencias del campo psi, su textualización ha originado géneros de escritura. Estos incluyen diferentes versiones más ortodoxas o heterodoxas clasificables de acuerdo con sus argumentos principales, revisiones críticas, modelos regionales, modos de acumulación particulares y otras lógicas de poder y violencia.

Este artículo no busca debatir los argumentos dominantes que articulan sufrimientos y campo psi en poblaciones marginalizadas, o debatir e incluso refutar sus estatutos de facticidad desde otras perspectivas y experiencias. El problema consiste en que hay experiencias y realidades que traspasan los argumentos y perspectivas dominantes que cartografían dolencias. Después de investigar y escribir dentro de estos géneros de literatura académica, puedo decir que hay demasiado que se escurre a través de ellos. Y no solo se trata de sufrimientos y tragedias, sino de un repertorio de malestares que se confunden y mimetizan con modificaciones de los modos de vivir (habitar, sentir, hablar, escuchar, trabajar) generadas en los márgenes urbanos, por las transformaciones económicas, políticas y territoriales que tuvieron lugar en Argentina en las últimas décadas (Epele 2016; Fernández 2016; Harvey 2004).

En la investigación sobre psicoterapias, padecimientos y pobreza, lo que excede a estos modelos no son eventos extraordinarios ni estridentes, sino malestares, un repertorio de afecciones y aflicciones que erosionan y dan forma a lo cotidiano en estos contextos sociales. Además, estos malestares no se disocian y están en la misma escala cotidiana de las condiciones materiales de vida, de injusticia y marginación. Específicamente, son detalles menores: ciertas experiencias, algunas acciones, experiencias corporales, modos de poner los cuerpos, de decir ciertas palabras, realizar ciertos trabajos, padecer dolores, hacer silencios, producir ritmos, sentir ciertas emociones. A diferencia de las dolencias, categorizadas en términos expertos y nativos que han sido objeto de las investigaciones clásicas en antropología, estos malestares son invisibilizados y minimizados, ya que no llegan a tener una consistencia, una entidad, un nombre. Por lo tanto, hablar de malestares menores no se refiere a una valoración estadística, de gravedad, nivel de desventura, grado de desasosiego y tragedia que los caracterizan. Investigar sobre estos malestares exige modificar los umbrales de sensibilidad para el registro en detalle de zonas de experiencia imprecisas y 
que tiñen, inevitablemente, con cierta ambigüedad el lenguaje que las describe. Entonces, con la apertura de la sensibilidad a otros modos de expresar malestares es posible dar luz, inteligibilidad y hacer escribible aquello que permanece indiferenciado, minimizado e innombrado bajo las perspectivas dominantes.

Deleuze y Guattari (1975), en su análisis sobre las literaturas y las luchas por la enunciación, capturan el carácter completamente político de las escrituras menores. Desde esta perspectiva, el término menor de una literatura refiere y expresa a una minoría que habla y habita la lengua mayor como extranjero o inmigrante (Biehl 2005). A diferencia de lo mayoritario, dominante, marginal y popular, la escritura menor se refiere a una minoría que privilegia el problema individual y lo hace por completo político. La enunciación minoritaria, debido a su posición frágil con respecto a lo mayoritario, se entiende como una acción colectiva con el potencial de forjar otra sensibilidad y comunidad. De este modo, la literatura menor o minoritaria no se refiere a algo marginal, desviado o estadísticamente poco representativo, sino a sus condiciones revolucionarias de elaborar otras economías discursivas y nuevas expresividades.

Siguiendo a Deleuze y Guattari (1975), la escritura a contracorriente en este artículo supone escribir sobre aquellos malestares que se escurren y pierden a través de los argumentos y cartografías dominantes sobre los sufrimientos y las dolencias en contextos de desigualdad y marginación. Principalmente, escribir sobre esta temática se convierte en desafiar lo establecido, lo decible con relación a una problemática específica y en un momento social, histórico y político. Es decir, investigar a contracorriente tiene como característica fundante hacerlo en un lenguaje y una escritura que se ven afectados irremediablemente por el mismo proceso que los posibilita (Deleuze y Guattari 2004).

\section{La investigación}

En diferentes estudios etnográficos sobre problemáticas de salud que he realizado en barrios y asentamientos marginalizados de Buenos Aires, las psicoterapias en los centros barriales de salud emergían como uno de los pocos recursos accesibles y demandados por las poblaciones de esas zonas. Con el fin de investigar las complejas relaciones entre psicoterapias y pobreza en condiciones de marginación neoliberal, he realizado una etnografía por un periodo de cuatro años (2013-2017). Considerando que la mayoría de las investigaciones sobre terapéuticas $p s i$ se han enfocado en el psicoanálisis practicado por las clases medias y élites urbanas de Buenos Aires, este estudio busca describir y analizar las características de las tecnologías psicoterapéuticas orientadas a poblaciones hasta 
ahora relegadas en la investigación. El objetivo general consiste en describir y analizar los vínculos entre los cambios en los problemas, las dolencias y los malestares en la vida cotidiana de los márgenes urbanos.

El trabajo de campo fue llevado a cabo en dos áreas de barrios caracterizados por la segregación territorial, elevados índices de violencia, desempleo generalizado con actividades laborales precarias y flexibles en economías informales y formales, generalización de planes y subsidios estatales, crecimiento de economías ilegales, deterioro y progresiva privatización de los sistemas públicos de educación y salud, incremento del consumo problemático de drogas, fragilidad habitacional y hacinamiento, aumento de la criminalización y persecuciones por parte de diferentes fuerzas públicas. A su vez, si bien durante el trabajo de campo se fue registrando un deterioro progresivo en las condiciones materiales de vida, en los últimos dos años adoptó características de crisis económica, como el incremento de la demanda de alimentos y medicamentos, su posterior reducción y ajuste, y la rápida caída de actividades económicas formales e informales.

El trabajo etnográfico estuvo centrado en tres técnicas principales. En primer lugar, se realizaron entrevistas a 30 psicólogos (24 mujeres y 6 varones), así como a otros profesionales de la salud (10) y 30 pacientes (21 mujeres y 9 varones), todos mayores de 18 años. En segundo lugar, la observación participante fue llevada a cabo en los centros de salud, en diferentes actividades institucionales y en espacios de la cotidianeidad (comedores, viviendas, plazas, bares, centros culturales, etc.). En tercer lugar, y como parte del trabajo de campo etnográfico en contextos institucionales y barriales, se incluyó la estrategia de seguir ciertos casos en diferentes ámbitos sociales por un periodo de tiempo, que ha sido desarrollada en el campo de laantropología de la salud (Biehl 2005). Este estudio aumenta el poder analítico de las técnicas clásicas (participación, entrevista, etc.) para registrar algunos problemas y malestares que no llegan a ser categorizados en diagnósticos o nociones locales, y que están atravesados por fricciones y conflictos entre diferentes experiencias, saberes y prácticas. Los casos fueron seguidos durante seis meses a un año. Esta técnica estructura el artículo, debido a que hace posible problematizar en términos de la vida cotidiana aquellos malestares que quedarían invisibilizados con el uso de otras metodologías.

La mayoría de los residentes que se transforman en pacientes tienen niveles de ingreso cercanos o por debajo de la línea de la pobreza. Entre los trabajos más usuales, ya sean asalariados, precarios o formales, podemos destacar: servicio doméstico, servicios de limpieza, seguridad profesional o no en compañías privadas y agencias gubernamentales. Con respecto a los niveles de educación, la mayoría ha finalizado la escuela primaria y solo excepcionalmente han cursado 
algunos años de la secundaria. Esta investigación se ha enfocado en casos como el de Martín, que llegan a la consulta sin intermediación institucional alguna. Es preciso destacar que la investigación fue aprobada por el Comité de Ética de la Facultad de Ciencias Sociales de la Universidad de Buenos Aires (UBA), y se siguieron sus lineamientos referidos al consentimiento informado, la confidencialidad sobre el lugar dentro de la ciudad de Buenos Aires donde se desarrolló el trabajo de campo y la identidad de los participantes.

\section{Lo sensible, lo decible y lo audible}

El sol caía temprano, casi a media tarde. Era uno de esos días cortos de invierno cuando pasé por donde vivía Martín, como habíamos quedado. No era la primera vez que visitaba estas viviendas: departamentos pequeños, piezas con un baño, en un complejo multifamiliar de grandes dimensiones con un alto grado de hacinamiento que, como él decía, “cualquier día se viene abajo por el peso de tanta gente”.

Estar ahí revolucionó mis sentidos. Como un vórtice de lo sensible, me hizo interrogar ciertas ecuaciones sensorio-conceptuales que se dan por supuestas en la vida cotidiana. Como en muchos barrios populares, el sonido de la música que se escuchaba en esta vivienda era muy fuerte ese día. Las conversaciones, de elevado volumen, confundían géneros, tonos, temas y autoría en patios y pasillos. La estructura edilicia era tan endeble que los modos de sentir, las resonancias, vibraciones y ecos hacían del sonido y del ruido una experiencia corporal, material, algo ineludible.

En vez de escuchar, siguiendo aquel circuito que los expertos han descrito sobre este proceso (sonido exterior - oído - centro neurológico - identificación del tipo de sonido: música), en estas viviendas se hacía inevitable sentir el sonido como algo corporal, fusionado con el ambiente. De alguna forma, la música era sentida desde adentro del cuerpo: el tórax se convertía en una caja de resonancia. Era sentida más que oída. Además, el temblor rítmico de las estructuras de los edificios hacía del caminar una empresa difícil. Confrontando con los estudios que disocian las experiencias corporales, las maneras de sentirlas y los lenguajes para representarlas en categorías discretas, estos modos corporales de sentir y decir los sonidos aglutinan y ensamblan diferentes materiales (palabras, músicas, maderas, cuerpos, etc.). Cada fibra sensorial de los pies y el cuerpo sentían vibraciones mientras las paredes, los vidrios y las puertas chirriaban, hacían ruido al entrar en fricción entre sí. Martín decía que la música y los ruidos iban creciendo en amplitud, escala y diversidad a medida que la tarde se volvía noche, 
especialmente los fines de semana. Algunos vecinos no dormían hasta la madrugada. Los que querían dormir no podían. Por esas "cosas buenas que solo se dan", él tenía justo el turno tarde-noche y su hijo no se veía afectado, solo la persona que lo cuidaba. Los ritmos cotidianos, las horas de trabajo, de dormir, hablar, mirar y escuchar se habían organizado contemplando estas particularidades.

A Martín lo había conocido meses atrás, en los inicios de mi trabajo de campo. Cuando me presenté él dijo que le gustaría participar en la investigación. Al leer el consentimiento informado comenzó a preguntarme en detalle más que sobre la investigación, sobre mi trabajo como antropóloga. Las preguntas de Martín iban rompiendo y disolviendo la coraza hecha de expectativas académicas acumuladas, solidificadas en las genealogías de argumentos que todo inicio de trabajo de campo incluye.

Martín hablaba lentamente, con cuidado, tomándose un tiempo extra en cada enunciación. Era como si estuviera diciendo palabras y frases por primera vez o en una lengua extranjera. A sus treinta años, parecía tener ya experiencia en crear este clima especial en el que se pone nombre a las cosas por primera vez. Él tenía cierta práctica en advertir en qué consistían estos “juegos del lenguaje”, en reconocerlos como juegos y buscar ir más allá de eso, como intuyendo que rompía, con su simple decir, sofisticadas teorías europeas sobre el lenguaje.

"Estoy empezando a hablar", me dijo, "siempre estuve muy para adentro". Decía que pertenecía a la ya reducida y transformada clase trabajadora de los márgenes de Buenos Aires. Al padre nunca lo conoció. Su madre sola tuvo que dejarlo con su abuela a los tres años. Tenía que trabajar "cama adentro".

Nunca entendí por qué me dejó. Y nadie me hablaba, nadie explicaba nada, yo no entendía. En el colegio decían que tenía problemas de aprendizaje y por eso andaba mal de conducta. Me trataban como discapacitado, pero yo... es que me sentía solo y abandonado. Nadie me miraba, nadie me hablaba. Nunca encajé, siempre tuve la sensación de que tenía que estar en otro lugar. (Fragmento de entrevista, 2016)

Al preguntarle si esto lo hablaba con alguien, Martín decía de sus seres cercanos que:

[...] no son buenos oyentes, no saben escuchar... alguien que te permita desahogarte a vos y ya está. Después habla vos de lo que quieras... pero no. A mí me cuesta... eh... decir las cosas... Me cuesta mucho... decir las cosas. Ahora este año más o menos empecé a... a... Bueno, más o menos, el año pasado empecé a hablar... bien en claro las cosas. El tema de vida, temas personales, que yo lo tenía muy, muy adentro. Por ejemplo, el tema de mi nene, Pablito. Sí, me cuesta decirlo, porque... qué sé yo... mi nene es sordo, hipoacúsico. Nació así. Él tiene como una cáscara, el 
sonido no entra en él. Entonces, del colegio me dijeron que tenía que llevarlo a otro lugar, porque está distraído. Ellos dicen que es porque la madre lo dejó. Pero para mí es otra cosa, para mí es porque es sordo, y el colegio es malo, no lo ayudan. Ellos dicen que es por la mamá, que es lo emocional. Me dijeron que tenía que ir a un centro terapéutico, pero no era lo que esperaba. Era como... yo no quiero que mi nene esté ahí, un depósito... porque no tengo plata para pagar algo bueno. Ahí no le tienen paciencia, porque conmigo responde. Yo le hablo, siempre le hablo, le digo "Pablo, vamos a comer", “dale, Pablo”, "sentate acá”, así, le hablo porque es mi hijo. Más allá de que él me vea y sepa, yo le hablo, no estoy mudo, le hablo. (Fragmento de entrevista 2016)

Cuando le pregunté cómo llegó a hacer psicoterapia, Martín hizo una pausa, un silencio, para decir: "para hablar con alguien, quizás, el hecho de ver qué es lo que pasa”. Aquellos que llegan a la consulta sin derivación profesional exponían como fuentes de la consulta diferentes problemas en contextos de marginación a los que se les suman los modos en que la desigualdad económica, política y social afectan la manera de hablar, escuchar, decir y enunciar, en medio de palabras y silencios, sonidos y ruidos en estos barrios. Entre el repertorio de estas afecciones registradas en el curso del trabajo de campo encontramos algunas expresiones como:

"eh... temas de inseguridad... de no tener bien claro, bien... adónde iba, y demás, esas cosas”, "vengo con la intención de buscar un hueco”; "no tengo nadie que me escuche"; "te prestan la cara pero no entienden nada"; "estoy muy sola y no puedo hablar con nadie"; "hablo con la gente, pero hay cosas que no puedo decir”; "tenía algo muy adentro, que lo tengo que sacar”; “tengo miedo de hablar”; "para mi familia, hablo yo, y pasa un tren"; "estoy como aturdida, confundida”; "con los ruidos no puedo dormir”, "hay que hablar, pero de veras”, "sentir que el otro escucha”, "hay que abrir, si no, no pasa nada, hablar... así empieza”. Para Martín: "Y bueno, vine... y empecé hablar con ella [la psicóloga] y... me siento mejor.

— ¿Hablar acá, ¿cómo es?

- Hablar... hablar en el sentido de que... qué sé yo, le podés contar cosas que quizás otra... a una persona más de confianza, no sé, yo no podría hablarle así.

— ¿Con otra persona?

- Con otra persona... un tercero aparte, totalmente desconocido, a mí me ayuda más. No tengo idea. Pero venir acá... no tengo idea, pero me ayuda más. [...] En cambio, con otras personas que ya me conocen o... o... me cuesta más... es como que... Uh... [con una expresión abrumada]. (Nota de campo 2016) 
Habiendo nacido en el barrio donde vivían sus abuelos, Martín decía "ser” del barrio, de un "barrio mediopobre”, “duro”, pero ahí se sentía “en casa”. Aunque tenía un trabajo que le permitía atenderse bajo la precaria cobertura de una obra social "mala o para pobres”, prefería ir al centro de salud barrial: "me queda cerca, las psicólogas eran muy agradables”, y le pareció que le iba a ser "más fácil hacer tratamiento ahí”. En resumen, le quedaba cerca en todos los aspectos.

Martín tenía un trabajo desde hacía cinco años en una empresa tercerizada de vigilancia. Esos trabajos de los llamados precarios o flexibles no eran flexibles a su favor. Él comenzó lentamente a narrarme el modo como "arrancar a hablar” en el tratamiento hizo posible hablar de otros modos, en otros contextos:

Me acuerdo una vez con mi encargado que... a mí me habían cambiado de horario y yo... laburo de 8 a 3... de la mañana y me habían cambiado. [...] Después saliendo más tarde es como que ya... como que... yo tenía una rutina y me la cambiaron y ahí ya me dieron vuelta la cabeza y... Tenía problemas en el trabajo, hasta que un día dije... a mi encargado... que me haga el favor.

— ¿Nunca lo habías dicho?

—Nunca lo había dicho. Y él me dijo: “¿Por qué no me lo dijiste? Lo podíamos haber hablado, lo podíamos haber evitado”. Y después sí... me cambiaron el horario y para mí fue un alivio. Hasta el día de hoy me pregunta cómo está mi nene y demás... Y sí, le digo. Como que yo no hablo mucho con otra gente, no quiero que me digan... “Uh, pobre Martín”. (Nota de campo 2016)

En los diferentes contextos barriales, la mayoría de las personas que por momentos o por ciertos periodos de tiempo se convierten en pacientes, conversan y comentan eventos cotidianos, participan en comedores, merenderos, fiestas escolares, iglesias, organizaciones barriales, partidarias y políticas. Por un lado, estos contextos están atravesados por diferentes tipos de discursos, narrativas típicas sobre ciertas experiencias, formas de historizar eventos significativos, modos de quejarse, demandar y protestar que son producidos y reproducidos colectivamente. Entre estos casos figuran: los cierres de calles y rutas de transporte (conocidos como piquetes), las demandas de alimentos a organismos estatales, las marchas, las protestas y las movilizaciones por programas y planes sociales. Por el otro lado, están aquellos problemas que se vuelven dominantes y visibles para las categorizaciones locales y diagnósticos psi (depresión, ansiedad, ataques de pánico, violencia de género, adicciones, abusos, duelos, etc.). En estas experiencias y dolencias confluyen saberes expertos ( $p s i$, judiciales, etc.) —algunos de ellos popularizados-, tradiciones locales para entenderlos, modos de sentirlos y 
caracterizarlos. Sin embargo, hay todo un repertorio de malestares ligados a las condiciones materiales y sociales que no llega a incluirse en esta trama discursiva y enunciativa, entre los que podemos destacar modos de enunciar, hablar y escuchar afectados por los sonidos, ruidos, fragilidad y falta de privacidad en las viviendas; dificultades en los ritmos de vigilia y sueño relacionados con otros ritmos que dominan en el barrio; dificultades para enunciar problemas dentro de los regímenes de trabajo precario; convivencia con estereotipos y estigmas ligados a la falta de reconocimiento de la diversidad en instituciones (relacionados con la pobreza, la discapacidad, etc.); dificultades en el aprendizaje que se interpretan como personales aunque se asocian con la falta de acceso o adecuación en el sistema escolar.

Considerando el carácter heterogéneo de la gente que vive en estos barrios, el repertorio de malestares es tan amplio que solo se puede describir en relación con áreas donde la pobreza, la desigualdad y la marginación afectan la vida cotidiana. Entre ellos podemos destacar: las formas de producir ingresos (por ejemplo, a través del trabajo doméstico, ambulante e informal); la criminalización de la pobreza (persecución policial, marginación y exclusión de los puestos de trabajo formales); acceso y atención en el sistema de salud (esperas largas e inciertas para turnos y tratamientos, medicamentos de mala calidad, entre otros); desmantelamiento de redes sociales locales por la extensión de las economías ilegales e ilegalizadas (aumento de robos, conflictos por recursos, intrusiones en viviendas de otros vecinos, etc.). En otros casos, los malestares se refieren a los modos en que el trabajo y el desempleo crónico afectan las prácticas de crianza de los hijos; la atención y dedicación constante requeridas cuando los hijos tienen consumos problemáticos de narcóticos; las dificultades y obstáculos en seguir tratamientos por la gran afluencia de gente - incluso de las clases medias - en los centros de salud estatales, y dificultades para dormir por la creciente actividad delictiva en la noche.

En esta densa trama de discursos, narrativas y enunciaciones, "arrancar a hablar", "hablar de veras” y “abrir y hablar” de la mayoría de las personas que llegan al tratamiento tienen otro estatuto. En primer lugar, estas acciones no significan que no se hablen, conversen, expresen opiniones y posiciones entre los discursos y narrativas disponibles. En segundo lugar, no significa que desconozcan las políticas de la palabra que regulan las correspondencias entre contextos y enunciaciones. El “arrancar a hablar” de Martín, evidente en otros casos, incluye, de forma indisociable y simultánea, poner en palabras algo del malestar que incluye hablar de ciertos malestares que no están incluidos dentro el repertorio de dolencias psi, en los discursos, modos de narrar y expresiones 
que dominan en estos contextos sociales. Este es el caso, por ejemplo, en que los modos del decir se ven afectados por ciertos malestares (sonidos, ruidos, modos de hablar, etc.) que están presentes al vivir en edificaciones superpobladas, que afectan y son indisociables de los modos de enunciarlos. También, se refiere al malestar del decir sobre la discapacidad, decir acerca de los efectos de ciertos discursos sobre la pobreza y de las miradas estigmatizantes en las escuelas sobre las dificultades de los niños que han afectado a los sujetos que las enuncian.

Estas afecciones, que en ocasiones los mismos sujetos (individuales y colectivos) se ven forzados a asumir en la misma acción de decirlas, se ven cuestionadas. Es preciso señalar que los tratamientos no son la única posibilidad de que estos malestares y los modos de enunciarlos emerjan; también pueden hacerlo en otros contextos sociales, como el de los vínculos cercanos y las amistades.

En uno de los últimos encuentros, Martín describía en detalle las características de las experiencias de hablar y escuchar en los modos de tratar con la palabra en esta trama barrial:

Una especie de espejo. Es como que... digamos, yo estoy hablando con vos en el espejo, y después yo... me digo... "pero ya lo dijiste, ya lo hablaste...”. Por ejemplo, ella me dice... lo mismo que digo yo... pero como preguntando y ahí... vos te das cuenta. Es como que de repente... ipup! Te prende la luz. Y decís, "sí".

Es como que vos estás así apagado y... viene y se te hace ipum!, mirá, todo este camino lo recorriste vos, pero no porque vos quisiste, porque te dijeron, te ordenaron o... dijeron: "vamos por acá", y yo voy, ¿me entendés? Nunca tomé un camino propio, una decisión propia. Y ahora que me doy cuenta... sí, sí es verdad. (Fragmento de entrevista 2017)

Después de conocer a algunas personas cuyos padecimientos se correspondían con aquellos grandes sistemas de categorías con las que se clasificaba la demanda en salud mental de estas poblaciones (violencias y abusos, depresión, consumos problemáticos, trastornos, etc.), Martín parecía una excepción. Aunque tenía características sociobiográficas similares a las de otros miembros de esta población en el área de Buenos Aires, había dos aspectos que lo diferenciaban de la mayoría de las personas que llegaban al tratamiento. Por un lado, en un contexto de desempleo creciente, demanda en aumento de subsidios sociales y rápido incremento del costo de vida a causa de los ajustes estructurales implementados por el Gobierno nacional desde el 2016, Martín tenía trabajo, aunque precario, flexible y de salario por debajo de la línea de la pobreza. Por otro lado, Martín decía que experimentaba ciertos malestares, sin nombre ni mucha 
entidad, pero que tenían el empuje necesario para llevarlo a la consulta en el centro barrial de salud.

Como si intuyera que lo que decía, insinuaba y expresaba - de modo no voluntario ni intencional - iba transformando las maneras de decir y escuchar en nuestros encuentros, se fue tejiendo una trama enunciativa y de inteligibilidad particular. Esta trama marcaba la apertura del decir individual a los otros, haciendo de la enunciación un problema colectivo. Además, fue poniendo en evidencia la frágil pero continua acumulación, fusión y mezcla de lo vivido y realizado en nuestros encuentros, convirtiéndolos en insumos y materiales de arreglos enunciativos particulares.

Por lo tanto, el caso de Martín - con los elementos que traigo de otros o de lo que el caso de él dice por los otros-requiere ser examinado a través de diferentes órdenes analíticos: 1) en lugar de reforzar —o negar - la ya establecida asociación entre desigualdad, pobreza y catástrofes de sufrimiento y salud, el presente análisis permite la inmersión en el mundo de malestares casi imperceptibles y silenciosos, que están hechos de la materia misma de las sensibilidades, las relaciones sociales, las políticas y económicas, es decir, de lo que están hechas la desigualdad y la marginación. 2) Hablar de minimalismo refiere también a umbrales sensoriales y de inteligibilidad. De alguna manera, el carácter menor de los malestares alude a que no son detectables, puesto que se filtran a través de los sistemas de categorías y los argumentos de las disciplinas psi, las categorías legales y locales, y las disponibles en las ciencias sociales.

\section{Economías de malestares}

Ya finalizado el trabajo de campo, el caso de Martín estaba lejos de ser una excepción. Durante su desarrollo se agregaron otros casos semejantes que se distinguían por dos características centrales: el trabajo precario y flexible, por un lado, y padecer malestares sin nombres o diagnósticos (ya fueran expertos o legos). Este agrupamiento de personas que llegan a la consulta en centros barriales de salud devino en un conjunto frágil y temporario, una minoría respecto a la mayoría que combinaba diferentes estrategias de obtención de recursos (planes estatales, trabajos informales y diarios, etc.). El agrupamiento inhibe su individuación, ya que moviliza conjuntos de personas, aunque también se resiste a ser transformado en un colectivo semejante a otras organizaciones en estas poblaciones. Además, el conjunto tiene características imprecisas, heterogéneas y de orígenes diversos (reproducción de las poblaciones locales, migraciones internas e internacionales, movilidad social descendente, etc.). 
Como una extensa literatura ha analizado, las reformas económicas y estructurales durante las últimas décadas han modificado las características del trabajo asalariado, las actividades laborales en general, las economías locales y la territorialización de la pobreza y la marginación (Basualdo 2001; Svampa 2005). Con el avance del régimen neoliberal, el trabajo precario y flexible se convirtió en problemático y minoritario en estas poblaciones, frente al desempleo formal generalizado y a la dominante combinación de diferentes estrategias de sustento: planes sociales, trabajos en economías informales e ilegalizadas, y actividades ilegales (Epele 2010; Fernández 2016; Grimberg, Fernández y Carvalho 2009).

Además de los cambios y restricciones en derechos laborales, cuando en el barrio se hablaba de las características de los trabajos precarios y flexibles, quienes subsistían (principal o exclusivamente) a través de esta clase de empleo señalaron la presencia de los siguientes rasgos: amenazas de ser despedidos sin fundamento por la rápida y fácil sustitución de una persona; despidos con motivos encubiertos (problemas de salud propios o de un familiar, enfermedad infecciosa, orientación sexual, embarazo, residencia en villa, etc.) y cambios abruptos y unilaterales en las condiciones laborales (como sueldo y horario).

Por otro lado, estos márgenes urbanos se caracterizan por la precariedad habitacional estructural, la falta de reformas orientadas a la reducción de la desigualdad social y territorial, y el deterioro de sistemas públicos tanto educativos como de salud. A su vez, la confluencia de un conjunto de procesos (la cíclica reducción de los ingresos, los desmantelamientos de ciertas actividades informales, la ilegalización de otras, etc.) ha promovido la progresiva dependencia y normalización de los regímenes laborales orientados a la subsistencia mínima, en y por debajo de los umbrales de pobreza. Por lo tanto, y desde diferentes perspectivas, el trabajo en su multiplicidad viene y sigue siendo uno de los sensores más agudos acerca de los modos en que la desigualdad y la pobreza se han producido, reproducido y normalizado en las últimas décadas (Svampa 2005, 2016).

Acompañando estas transformaciones, no solo el repertorio de dolencias, problemas y motivos de consulta se ha modificado, también han cambiado los sistemas de clasificación diagnóstica, sus genealogías y centros de origen, los lenguajes expertos acerca de las dolencias y los modos de tratarlas (Onocko et al. 2008; Ortiz, López y Borges 2007). Sin embargo, los malestares que condujeron a Martín a la consulta psi no llegaban a tener nombre, diagnóstico, y mucho menos una entidad reconocida como para ser patologizados e integrados a los sistemas de diagnóstico estandarizados de los profesionales $\mathrm{y}$, a través de la psicologización, apropiados por los actores sociales. Estos malestares son enunciados 
conjuntamente y a través de la narración de las experiencias y situaciones en las que son vividos.

A diferencia de las categorías expertas psi, de aquellas denominadas "locales" o "nativas", y de las combinaciones entre ambas, estos malestares se resisten a ser subsumidos y capturados en los circuitos de patologización, psicologización, objetivación, individualización y reapropiación local que dominan las dolencias psi en estos espacios sociales (Rose 1998). De alguna forma, estos modos de malestar no llevan a despegarse y diferenciarse del vivir en general, es decir, refieren a las formas de habitar, trabajar, sentir, pensar(se) y relacionarse, que se han convertido en blanco privilegiado de la destrucción creativa que, siguiendo a Harvey (2006), desarman y rearman la vida ordinaria en estas poblaciones. Estos malestares se mimetizan, confunden y transforman con modos de estar, de hacer y vivir, al mismo tiempo que evocan otras economías, de bienestar, sistemas educativos y de salud, políticas de lo sensible y lógicas de reciprocidad y sociabilidad. Atravesando el amplio espectro de lo cotidiano, tanto en el caso examinado como en otros, estos malestares se concentraban principalmente en el hablar y el escuchar, en los modos de habitar las viviendas, de trabajar, dormir, aprender en las escuelas y crecer con otros parientes.

En estos malestares confluyen una economía y una política articuladas y producidas por los abruptos y cíclicos cambios en la vida cotidiana en los márgenes urbanos. Por un lado, hay una economía de los malestares, es decir, un repertorio de experiencias, prácticas, expresiones corporales y verbales modeladas por transformaciones neoliberales que producen y reproducen la pobreza y la marginación (trabajo precario, desempleo, insuficiencia de viviendas, etc.). Por el otro, hay políticas de la palabra, es decir, formas y condiciones de tomar la palabra, tramas discursivas y modos de narrar y de enunciar que distribuyen lo decible, lo audible y lo inteligible con respecto a lenguajes mayoritarios y menores en contextos sociales específicos. También, estos movimientos de enunciación conmueven los bordes entre el yo y el otro, los cuerpos y ambientes, los discursos establecidos y emergentes, las economías y las políticas en los márgenes urbanos.

\section{Afectos, intensidades y dialectos}

El análisis de las formas de decir y padecer exige su contextualización en las diferentes relaciones entre dolencias y lenguajes en sectores segregados, que se pueden sistematizar en dos orientaciones principales. En primer lugar, encontramos aquella orientación general que incluye diferentes modos de representación ya que diferencia analíticamente la experiencia corporal y emocional de las 
expresiones lingüísticas (Dias 1986; Kleinman, Das y Lock 1997; Lakoff 2005; Visacovsky 2009). Entre las ecuaciones analíticas de esta orientación están: la patologización individualizante de dolencias en términos de diagnósticos psi; la categorización de los malestares y dolencias en términos de nociones nativas y locales que se corresponden con experiencias características y compartidas por las poblaciones; la apropiación por parte de los conjuntos sociales de diagnósticos expertos y categorías de dolencias extranjeras respecto de los contextos locales, a través no solo de procesos terapéuticos sino también de los medios y tecnologías de comunicación; la emergencia de clases y géneros del decir y narrar sobre los padecimientos formulados en términos de problemas sociales (violencias, consumos problemáticos, etc.), y que modelan discursos sociales, políticos y académicos.

Este mapa de ecuaciones analíticas acerca de las dolencias en sectores marginalizados no solo habla del amplio espectro de epistemologías, lógicas y políticas para abordarlas. También saca a la luz un amplio, fragmentado y heterogéneo repertorio de dolencias, maneras de sufrir y de malestar en estos contextos sociales. Sin embargo, estas perspectivas se muestran impotentes, es decir, sin los poderes de resolución necesarios para capturar los malestares que se analizan en este trabajo. Al no tener nombre, entidad, ni consistencia que conduzca y traduzca por los cauces tradicionales hacia el lenguaje, para problematizar estos malestares se hace necesario ubicarlos en una segunda orientación de análisis. Esta orientación elude, prescinde, se resiste o confronta directamente la representación, el lenguaje y los signos como estratos que se corresponden y abstraen del vivir, sentir y padecer (Csordas 1994; Das 2007; Favret-Saada 1980, 2012). Dentro de esta segunda orientación hay también diferenciaciones. En primer lugar, encontramos aquellos análisis que se enfocan en las experiencias de malestar en términos corporales y emocionales. Estas experiencias corporales exceden el lenguaje verbal, es decir, solo son susceptibles de ser capturadas por la representación y la textualización, a condición de ser atravesados por las aproximaciones fenomenológicas y hermenéuticas.

En segundo lugar, encontramos el ser afectado y los afectos. Formulada originalmente en el campo de la brujería y terapias en general, esta perspectiva cuestiona el privilegio de la palabra, la representación y las acciones en los rituales y terapias. Favret-Saada (2012) se refiere a una fuerza, a afectos anteriores a la representación, que consiste en ser afectado por la experimentación directa de vivencias. Como comunicación involuntaria e inconsciente, diluye la disociación sujeto/objeto y se corresponde con una metodología de participación centrada en el dejarse ser afectado que, solo a posteriori, hace posible su análisis y escritura. 
Ambas perspectivas comparten el hecho de que el lenguaje y la representación son marginados y no son revisados en sus características y poderes sobre lo sensible y lo vivible.

A diferencia de los anteriores, Deleuze y Guattari (2004) abordan diferentes regímenes de signos — sus mezclas y contaminaciones entre sí- como algo más -y menos - que el lenguaje, tal como es analizado por la lingüística. Estos regímenes no son relaciones entre las palabras y las cosas. Al contrario, son entendidos como arreglos que combinan cuerpos, deseos, sustancias, tecnologías, y flujos materiales y energéticos. Lejos de corresponder a la lengua en sentido tradicional, estos arreglos, siempre políticos y revolucionarios, asumen una enunciación colectiva y conforman lenguajes menores con relación a aquellos lenguajes mayores, ya establecidos como patrón de legitimidad y normalidad en contextos sociales específicos.

En estos enfoques, la intensidad, expresada en términos ya sea de afectos o emociones adquiere relevancia, ya que varía, escala y se anula, modelando el flujo real de vivir. Pero esto no es suficiente. Al privilegiar las intensidades, no solo se conmueven las barreras entre sujeto y objeto, nosotros y los otros, sino que toda enunciación, incluso la aparentemente individual, se entiende como un arreglo colectivo de flujos materiales y expresivos.

Como hemos mencionado en apartados anteriores, en el repertorio de las afecciones y aflicciones registradas, algunas se corresponden con malestares (corporales, experiencias ambientales, edilicias, vinculares, persecuciones de fuerzas de seguridad, etc.) que no necesariamente son expresados verbalmente, descritos y denominados de forma clara, completa y extensa por los actores sociales. Algunos son insinuados; otros, señalados en el curso de las experiencias, y otros, incluso, suceden mientras se desarrollan otras prácticas y tareas. Este trabajo focaliza aquellos malestares que llegan a los tratamientos centrados en la palabra, es decir, que son susceptibles - al menos en parte y de forma incompleta-de ser verbalizados: son expresados, acompañados o se articulan con ciertas palabras y expresiones. Como en toda etnografía, estos malestares son sometidos a un proceso de textualización que, a su vez, convierte lo vivido, dicho y registrado en escritura. Sin embargo, los modos de escribir las viñetas, describir los casos y hacerlos inteligibles se aproximan y se corresponden con el modelo de ensamble entre materiales diferentes y heterogéneos.

Desde este análisis los malestares son vividos como arreglos que ensamblan palabras, silencios, expresiones no verbales (soplidos, gemidos, risas, etc.), experiencias emocionales locales y especialmente aquellas marcadas por el encierro corporal, vibraciones por fragilidad en las viviendas, extrañeza con lo dicho 
y hecho en vínculos familiares, sometimiento e incertidumbre en las relaciones laborales, deseos de expresión y reconocimiento, invasión acústica de diferentes escalas de ruidos, y una multiplicidad de discursos establecidos cuyos fragmentos, palabras, tonos y modos de enunciación participan de la vida ordinaria de estos conjuntos sociales. Por último, a diferencia de aquellas perspectivas que proponen estos modos de decir como lenguajes marginales o populares (subalternos, de resistencia, etc.) (Deleuze y Guattari 1975), estos ensambles enunciativos y prácticas minoritarias dicen el padecer al tiempo que padecen el decir.

\section{Decir el padecer y padecer el decir}

Estas maneras de decir el padecer y padecer el decir no tienen lugar en el vacío. En el examen de los modos de malestar y en las formas de enunciarlos en el marco de los tratamientos en los centros locales del sistema de salud, confluyen regímenes de signos y lenguajes diferentes. Por un lado, encontramos las distribuciones de lo sensible que, en las sociedades capitalistas definen las particiones en centros y márgenes, lo visible - no visible, audible - no audible, decible - no decible. Mientras que algunos habitan y participan en lo visible, audible y decible, pueden tomar la palabra y hacerse entender, otros quedan en la oscuridad, el ruido o el silencio (Rancière 1996, 2009). Por otro lado, hay una multiplicidad de discursos sociales, políticos, académicos y psi que se ofrecen como lenguajes disponibles, inteligibles, aceptados y que brindan un conflictivo amparo, ya que, al subsumirse a ellos, exigen ser categorizados, marginados, discriminados, vulnerados o patologizados. Estos discursos y lenguajes (sociales, políticos, partidarios, disciplinares, religiosos, etc.), entre los que se encuentran los que componen el campo $p s i$, garantizan el acceso a ciertas palabras, nociones, clases de enunciación, modos de narrar, experiencias corporales, sonidos, ritmos y cadencias, modulaciones emocionales y modos de desencadenarlas, resonancias, silencios, causaciones y sentidos.

Para aquellos que llegan y atraviesan algunos de los circuitos - o tramosterapéuticos disponibles en estos barrios durante un periodo variable de tiempo, las relaciones entre hablar, trabajar y malestar hacen posible analizar las psicoterapias en contextos de pobreza desde ángulos que difieren de los argumentos tradicionales sobre esta problemática. Como diversos autores han señalado, las tecnologías terapéuticas en estas poblaciones asumen diferentes características. La mayoría exige a los pacientes ser categorizados por los discursos psi, asumir como propios diferentes lenguajes mayores de este campo o poner el cuerpo (con o sin fármacos o medicinas) en contextos terapéuticos, en ocasiones como 
contraparte obligatoria de diferentes intervenciones institucionales (educación, salud, justicia, etc.). Al considerar estas lógicas, los tratamientos centrados en la palabra pueden ser entendidos como una estrategia de psicologización, reduciendo o traduciendo lo económico, político y social en psi, orientada a multiplicar el control social en estas poblaciones.

Por otro lado, debido a los desafíos y particularidades que las poblaciones marginalizadas imponen a las psicoterapias, los psicólogos desarrollan cierta reflexividad de su propia actividad profesional al revisar y cuestionar estos procesos a través de la inclusión de otras perspectivas de ciencias sociales y de salud colectiva, sobre los padeceres y dolencias bajo condiciones de desigualdad y pobreza. Sin embargo, a la par, por fuera, o escurriéndose de estos procesos, hay una multiplicidad de experiencias y prácticas de decir el padecer y padecer el decir.

“El arrancar y hablar” sobre estos tipos de malestares en el contexto de los tratamientos centrados en la palabra consiste en ir ensamblando diferentes y variados materiales, no solo del ámbito terapéutico sino también de la vida ordinaria. Mientras que, en estos casos, se eluden y resisten los discursos y lenguajes mayores psi (sobre causas, diagnósticos, etc.), ciertas coordenadas de los tratamientos (como claves sociobiográficas, modos de narrar, causaciones y mapas de intensidades emocionales) van permeando y estructurando los modos de producir y desmantelar estos dialectos de los malestares.

Estos arreglos y ensambles siempre son colectivos porque no solo involucran más que a una persona, sino que incluyen, toman y acumulan materiales de las historias familiares, redes sociales, conjuntos poblacionales, características edilicias e institucionales del ambiente barrial en general. Entre estos materiales encontramos: palabras con carga afectiva, expresiones familiares, modos de organizar lo dicho y la narración, estructuras sociobiográficas, sollozos y llantos, ecos de lo oído y de lo dicho, vibraciones, ruidos ajenos, ver lo que se dice, resonancias corporales a partir de las palabras de otros, estallidos emocionales, preguntas abiertas, repetir y revisar lo dicho por otros. Además, estos modos de enunciar van conmoviendo no solo los registros locales de lo decible, también transforman las relaciones entre lo audible, lo sensible y los modos de hacer inteligibles las experiencias de malestar que se confunden y mimetizan con el vivir en estas poblaciones.

Desde esta perspectiva, los movimientos que incluyen el "arrancar a hablar”, el "hablar de veras”, "el abrir y decir”, en estos tratamientos y en la vida cotidiana, no pueden entenderse bajo las ecuaciones analíticas clásicas (pasividad-actividad, individual-colectivo, palabras-cosas, yo-otro, representación-realidad). Por un lado, lejos de la pasividad, los materiales terapéuticos (palabras, 
modos de decir, ritmos de enunciación, ser escuchado a través de repetir lo que el otro dice, etc.) son tomados como insumos para producir dialectos sobre malestares que exceden lo terapéutico, para decir, escuchar y vivir otras experiencias en la vida ordinaria. Por otro lado, la enunciación es siempre colectiva, ya que está hecha de insumos, como productos sociales compartidos y en relaciones con otros. Además, estas enunciaciones son siempre políticas: estos modos de hablar subvierten los discursos legitimados y los lenguajes habilitados para decir y sufrir en estas poblaciones. Por último, al expresar estos malestares que se mimetizan con la fragilidad y el deterioro de las condiciones de vida en estas poblaciones, los modos de enunciar se van transformando, siendo más permeables a que estos colonicen y produzcan lenguajes menores y nuevos dialectos, que conmueven los regímenes del sufrir, del decir y del vivir en los márgenes urbanos.

\section{Palabras finales}

En el último encuentro que tuvimos, Martín todavía estaba buscando una mejor escuela para su hijo. Difícil tarea para alguien con sus escasos recursos económicos, pues debe lidiar con las ya casi inexistentes vacantes en establecimientos públicos y gratuitos cercanos y con el desfinanciamiento de programas y organizaciones locales cuyo objetivo es la educación especial. Las intervenciones con la palabra no encuadraban en la clásica eficacia simbólica. Estos tratamientos tampoco revirtieron ni repararon injusticias sociales de larga data generadas por la desigualdad y la pobreza de la clase trabajadora — casi en extinción- en esta área geográfica que lo condenaban a trabajar para seguir siendo pobre. Martín ni siquiera se sumó a alguna organización barrial, solo "arrancó a hablar".

Frente al crecimiento de la desigualdad, la pobreza y las condiciones de marginación, incluso para aquellos pocos que tienen trabajos precarios por periodos inciertos de tiempo, estos frágiles arreglos enunciativos, dialectos subterráneos y movimientos casi imperceptibles del decir se resisten a ser incluidos en el repertorio de dolencias ya clásicas y en el mapa de argumentos antropológicos ya establecidos.

Escribir sobre los modos de decir estos malestares parecería algo "menor" frente a las grandes catástrofes de salud que enfrentan estas poblaciones. No obstante, esta escritura abre a la problematización ciertos modos de enunciar y de malestar que no son incluidos en los repertorios disponibles. Estos se mimetizan y transforman el habitar, el sentir, el hablar, el trabajar y el escuchar que desestabilizan la vida diaria, llegan a la consulta y exigen revisar los modos de argumentar sobre estos. En el caso de los padecimientos analizados en este 
trabajo, las dificultades en el hablar y el decir se expresan buscando hacerse visibles en los tratamientos de tipo psicoterapéutico que, a su vez, se enfocan en la palabra y en la escucha.

Los desmoronamientos, las reconstrucciones, los desmantelamientos y las reedificaciones cíclicas en las economías y políticas de los márgenes urbanos de Buenos Aires en las últimas décadas han modificado y precarizado la subsistencia y supervivencia de estas poblaciones. A su vez, los modos de enunciar los malestares y los malestares mismos se confunden e impregnan estos procesos, siempre colectivos, políticos y en peligro de destruirse también. Es decir, ensamblan de nuevos modos, escombros, restos y huellas de expresiones verbales, vibraciones, dinámicas de intensidad variable de afectos, frases de otros, deseos, movimientos, modos de narrar, micrológicas de razonar y resonancias de diverso orden.

\section{Referencias}

Abu-Lughod, Lila y Catherine Lutz. 1986. Language and the Politics of Emotion. Cambridge: Cambridge University Press.

Águila, Nicolás y Rubén Lo Vuolo. 2017. “Argentina y Brasil. Los límites de los regímenes de crecimiento liderados por el empleo y los salarios”. Documento de trabajo del Centro Interdisciplinario de las Políticas Públicas 94.

Basualdo, Eduardo. 2001. Sistema político y modelo de acumulación en Argentina. Notas sobre el transformismo argentino durante la valorización financiera (1976-2001). Buenos Aires: Flacso.

Biehl, Joao. 2005. Vita. Life in a Zone of Social Abandonment. Berkeley: University of California Press.

-. 2009. Will to Live. Aids and the Politics of Survival. Princeton: University of Princeton Press.

Biehl, Joao y Peter Locke. 2010. "Deleuze and the Anthropology of Becoming”. Current Anthropology 51 (3): 317-351.

Boltanski, Luc. 1999. The Distant Suffering. Cambridge: Cambridge University Press.

Bourdieu, Pierre. 1999. La miseria del mundo. Buenos Aires: Fondo de Cultura Económica.

Bourgois, Philippe y Jeff Schonberg. 2009. Righteous Dopefiend. Berkeley: University of California Press.

Briggs, Charles y Clara Mantini-Briggs. 2003. Stories in the Time of Cholera. Racial Profiling during a Medical Nightmare. Berkeley: University of California Press.

Csordas, Thomas. 1994. Embodiment and Experience. The Existential Ground of Culture and Self. Cambridge: Cambridge University Press. 
Das, Veena. 2007. Life and Words. Violence and the Descent into the Ordinary. Berkeley: University of California Press.

Deleuze, Gilles y Félix Guattari. 1975. Kafka, toward a Minor Literature. Minneapolis: University of Minnesota Press.

-. 2004. Mil mesetas. Capitalismo y esquizofrenia. Valencia: Pre-Textos.

Dias Duarte, Luiz Fernando. 1986. Da vida nervosa nas classes trabalhadoras urbanas. Río de Janeiro: Zahar.

Epele, María. 2010. Sujetar por la herida. Buenos Aires: Paidós.

-. 2016. "Psychotherapy, Psychoanalysis and Urban Poverty in Argentina". Anthropology \& Medicine 23 (3): 244-258. DOI: 10.1080 / 13648470.2016.1180664

—. 2019. "Sobre los argumentos y el argumentar. Modos de tratar con la palabra en los márgenes de Buenos Aires”. Revista Desacatos 60: 168-183.

Fassin, Didier. 2012. The Humanitarian Reason. Berkeley: University of California Press.

Favret-Saada, Jeanne. 1980. Deadly Words. Witchcraft on the Bocage. Cambridge: Cambridge University Press.

-. 2012. "Being Affected”. HAU Journal of Ethnographic Theory 2 (1): 435-445.

Fernández Álvarez, María Inés. 2016. La política afectada. Experiencias, trabajo y vida cotidiana en Brukman recuperada. Buenos Aires: Pro-Historia.

Foucault, Michel. 2007. El poder psiquiátrico. Buenos Aires: Fondo de Cultura Económica.

Grimberg, Mabel, María Inés Fernández Álvarez y Marcelo Carvalho Rosa, eds. 2009. Estado y movimientos sociales. Estudios etnográficos en Argentina y Brasil. Buenos Aires: Antropofagia.

Harvey, David. 2004. “The 'New' Imperialism: Accumulation by Dispossession”. Socialitst Register 40: 63-87. https://socialistregister.com/index.php/srv/article/view/5811/2707

-. 2006. "Neo-liberalism as Creative Destruction”. Geografiska Annaler 88 B (2): 145-158. https://is.cuni.cz/studium/predmety/index.php?do=download\&did=85806\&kod=JMMZ108

Jimeno, Myriam. 2004. Crimen pasional. Contribución a una antropología de las emociones. Bogotá: Universidad Nacional de Colombia.

Kleinman, Arthur. 1995. "Violence, Culture and the Politics of Trauma”. En Writing and the Margin. Discourse between Anthropology and Medicine, 173-189. Berkeley: University of California Press.

-. 2000. "Violence of Everyday Life. The Multiple Forms and Dynamics of Social Violence". En Violence and Subjectivity, editado por Veena Das, Arthur Kleinman, Mamphela Ramphele y Pamela Reynolds, 226-241. Berkeley: University of California Press.

Kleinman, Arthur y Joan Kleinman. 1991. "Suffering and its Professional Transformation: Toward an Ethnography of the Interpersonal Experience”. Culture, Medicine and Psychiatry 15: 275. 
Kleinman, Arthur, Veena Das y Margaret Lock, eds. 1997. Social Suffering. Berkeley: University of California Press.

Lakoff, Andrew. 2005. The Pharmaceutical Reason. Cambridge: Cambridge University Press.

Ortiz-Hernández, Luis, Sergio López Moreno y Guillerme Borges. 2007. "Desigualdad económica y salud mental: revisión de la literatura latinoamericana”. Cadernos de Saúde Pública 23 (6): 1255-1272.

Rancière, Jacques. 1996. El desacuerdo. Políticas y filosofía. Buenos Aires: Nueva Visión.

—. 2009. El reparto de lo sensible. Estética y política. Santiago: Lom.

Rose, Nikolas. 1998. Ourselves. Psychology, Power and Personhood. Cambridge: Cambridge University Press.

Salvia, Agustín, ed. 2018. Trabajo, salud y ejercicio urbano en la Argentina urbana (20102017). Documento Estadístico 1. Buenos Aires: Fundación Universidad Católica Argentina.

Scheper-Hughes, Nancy. 1992. Death without Weeping. The Violence of Everyday Life in Brazil. Berkeley: University of California Press.

Spivak, Gayatri. 1998. “¿Puede hablar el sujeto subalterno?”. Orbis Tertius III (6): 1-44.

Svampa, Maristella. 2005. La sociedad excluyente. La Argentina bajo el signo del neoliberalismo. Buenos Aires: Taurus.

—. 2016. Debates latinoamericanos. Indianismo, desarrollo, dependencia y populismo. Buenos Aires: Edhasa.

Tiscornia, Sofía, comp. 2004. Burocracias y violencias. Estudios de antropología jurídica. Buenos Aires: Antropofagia.

Visacovsky, Sergio. 2009. "La constitución de un sentido práctico. Del malestar cotidiano y el lugar del psicoanálisis en la Argentina”. Cuicuilco 45: 51-79. 